Espaço Aberto | Open Space

http://dx.doi.org/10.1590/S0104-71832021000300013

\title{
Argonautas, cem anos depois
}

\section{Argonauts, a hundred years later}

\author{
Mariza Peirano' \\ https://orcid.org/0000-0002-5674-2893 \\ mariza.peirano@gmail.com \\ ' Universidade de Brasília - Brasília, DF, Brasil
}




\title{
Resumo
}

Partindo da relação intrínseca entre teoria e etnografia, abordo neste artigo alguns dos motivos pelos quais, ainda hoje, Argonautas do Pacífico Ocidental é uma referência central para as ciências sociais. Precursor da pesquisa de campo intensiva, Malinowski definiu diretrizes, favoreceu novas teorias, nutriu ideais, formulou utopias e influenciou outras disciplinas das humanidades, tornando-se ele próprio uma figura mítica na antropologia. Deixou para as futuras gerações o desafio da procura do "ponto de vista nativo" e a elaboração de "teorias etnográficas". O texto aborda também o estilo de pesquisa anterior à de Malinowski, a forma da monografia, a relação entre seu diário de campo e as cartas escritas na época, e as reanálises a que o livro foi submetido.

Palavras-chave: teoria etnográfica; Argonautas do Pacífico Ocidental; Malinowski; trobriandeses.

\begin{abstract}
Starting from the intrinsic relationship between theory and ethnography, in this article I discuss some of the reasons why Argonauts of the Western Pacific is, even today, a central reference for the social sciences. A precursor of intensive field research, Malinowski defined guidelines, favored new theories, nurtured ideals, formulated utopias and influenced other humanities disciplines, becoming himself a mythological figure in anthropology. He left for the future generations the challenge of searching for the "native's point of view" and the elaboration of "ethnographic theories". The text also addresses the research style prior to Malinowski's, the form of the monograph, the relationship between his field diary and letters written at the time, and the reanalysis to which the book was submitted.
\end{abstract}

Keywords: ethnographic theory; Argonauts of the Western Pacific; Malinowski; trobrianders. 
Por muito tempo considerado um livro meramente etnográfico, foram necessárias várias décadas para que, na antropologia, ficasse evidente que a teoria é par indissociável da etnografia - foi então possível que Argonautas do Pacífico Ocidental, de Bronislaw Malinowski, recebesse o devido reconhecimento como marco da disciplina.

O caminho para essa avaliação não foi sem adversidades: em períodos alternados, Argonautas sofreu críticas e foi aplaudido. Em inglês, o livro nunca se esgotou, mas viveu um percurso frequente na antropologia como disciplina: livros e monografias, em determinado momento reconhecidos, ficam depois esquecidos, são redescobertos, apreciados, voltam como inspiração. O desenvolvimento da antropologia nunca foi linear; assim, apenas alguns livros se tornaram clássicos. Argonautas foi um deles e fez-se divisor de águas na história da disciplina. Como precursor da pesquisa de campo intensiva, criou padrões, definiu o trabalho etnográfico, favoreceu novas teorias, alimentou ideais e utopias. No centenário de sua publicação, Argonautas é referência para a antropologia e outras disciplinas das humanidades, como linguística, sociologia, economia. ${ }^{1}$

\section{Antes}

Malinowski não inventou a observação de campo, mas sua longa pesquisa entre os trobriandeses na Melanésia tornou-se célebre e adquiriu aspectos míticos como rito de iniciação na disciplina. O próprio Malinowski resumiu as condições necessárias para a pesquisa etnográfica em uma introdução à monografia que, por muito tempo, converteu-se em leitura obrigatória para estudantes. Antes da geração de Malinowski, pesquisadores baseavam-se em questionários e trocas de correspondência com missionários e viajantes para obter informações de povos pouco conhecidos. Retrospectivamente, como

1 No Brasil, o livro só foi traduzido e publicado em 1976, pela Editora Abril, mais de meio século depois de sua publicação original. É possível que a demora tenha resultado de sua caracterização como obra puramente etnográfica, exatamente quando a ênfase das novas ciências sociais no país era teórica. A mais recente edição é de 2018, pela Ubu, com novo prefácio e fotografias inéditas (Malinowski, 2018). 
os estudiosos não iam a campo, o período foi avaliado como a antiga fase da "antropologia de gabinete". ${ }^{2}$

Malinowski mudou esse cenário. Para muitos, fez uma revolução ao introduzir a ideia da "observação participante", derivada de sua longa permanência entre os trobriandeses da Melanésia (a primeira etapa, de 1915 a 1916, e a segunda, de outubro de 1917 a julho de 1918; na segunda, o kula já havia sido definido como o tema principal). Esse tipo de observação, ele acreditava, era desenvolvido para alcançar o "ponto de vista nativo", mais tarde tornado objetivo, ideal ou utopia de antropólogos. De forma implícita, tal intenção o levaria, por meio de alguns exemplos esparsos ao longo do livro, a retornar comparativamente ao mundo ocidental, em longo prazo para "enriquecer e aprofundar nossa própria visão do mundo, compreender nossa própria natureza e refiná-la intelectual e artisticamente" (Malinowski, 2018, p. 654). Aprendemos sobre nós com os outros.

Da metade para o final do século XIX, a objetividade havia se tornado condição indispensável para o conhecimento considerado científico no mundo ocidental. ${ }^{3}$ Naquele contexto, agentes missionários passaram a competir com cientistas naturais com o objetivo de sanar a curiosidade do ocidente em relação a nativos além-mar. Na Inglaterra, temos os exemplos de zoólogos, como Alfred Haddon e Walter Spencer; ou da expedição ao Estreito de Torres (18981899), em que psicólogos experimentais, médicos e linguistas como A. Haddon, W. H. R. Rivers, Charles Meyers e Charles Seligman deslocaram-se para a Melanésia para coletar material de campo. Até então, continuavam a trabalhar em inglês pidgin e, com frequência, com base em informações de viajantes, comerciantes e funcionários do governo. Essa é a fase da "antropologia de varanda", quando informantes nativos formavam filas para as entrevistas. Mas a expedição do Estreito de Torres indicou o caminho para uma etnografia mais intensiva. A pesquisa de A. R. Radcliffe-Brown entre os andamaneses (1906-1908)

2 Conferir Stocking Jr. (1983) para os precursores da antropologia e os primórdios da pesquisa de campo, mesmo antes da experiência de Malinowski.

3 Para a ideia de objetividade na ciência do século XIX, ver Daston e Galison (2007); para a influência na antropologia, ver Pels (2014). 
foi realizada ainda em pidgin e com desempregados em volta de um campo de prisioneiros em Fort Blair, na Baía de Bengala. ${ }^{4}$

Mas é com Rivers que a guinada ocorre. Na preparação da versão revisada do Notes and queries de 1912, com Haddon, Myers e Seligman, Rivers defendeu uma sistematização da experiência etnográfica: o pesquisador deveria conhecer a língua dos nativos, enfatizar o concreto para chegar ao abstrato, reconhecer que o nativo tem sempre uma motivação, usar de simpatia e tato, e considerar o emprego de termos nativos quando não reconhecesse uma categoria equivalente. Isso significava que o trabalho etnográfico não deveria seguir a divisão dos domínios que os "civilizados" distinguiam (como política, religião, educação, arte, tecnologia); essas esferas poderiam ser interdependentes e inseparáveis em outros povos (British Association for the Advancement of Science, 1912).

Malinowski seguiu esses passos e mudou o lugar da investigação etnográfica: nas palavras do historiador George Stocking Jr. (1983), da varanda da missão para o centro da aldeia. ${ }^{5}$ Assim, tanto manteve os princípios da objetividade da ciência já consagrados quanto introduziu a intersubjetividade entre pesquisador e nativos. ${ }^{6}$ Rivers havia mencionado simpatia e tato; Malinowski tornou-os centrais na pesquisa antropológica. Por essa defesa da comunicação na língua local e da permanência por longo tempo no campo da pesquisa, a procura de parâmetros científicos tanto quanto a comunicação entre etnógrafo e nativos fizeram-se viáveis e necessárias. Reconhecer o "ponto de vista nativo" demandava uma sintonia entre os envolvidos, o entendimento de que partilhavam uma mesma humanidade e de que identificavam sentimentos mútuos.

4 Antes da Primeira Guerra, Gunnar Landtman havia passado dois anos na Nova Guiné (19101912), porém perdeu seus dados em um naufrágio no retorno à Inglaterra. Conseguiu recuperá-los com mergulhadores, mas, exausto mentalmente, ficou incapaz de trabalhar os dados por muito tempo (Landtman, 1927). Malinowski reconheceu mais tarde, em 1929, a realização do contemporâneo, em muito semelhante à sua (Stocking Jr., 1983, p. 84).

5 Malinowski faz a mudança figurativa e literalmente, fincando sua barraca junto das habitações dos trobriandeses (Stocking Jr., 1983, p. 93).

6 Um longo caminho vai da intersubjetividade instaurada por Malinowski à pá de cal que Geertz (1983) joga na separação "nós vs. eles" quando anuncia que "agora somos todos nativos". Mais recentemente, Pina-Cabral (2006, p. 667) completa: "All natives can be ethnographers; [now] we have to come to terms with the fact that all ethnographers may be, and remain, natives." A pretensão de cientificidade de Malinowski consistiu na proposta de uma abordagem chamada de "funcionalista", suplantada depois pelo "estrutural-funcionalismo" de A. R. Radcliffe-Brown. 
Peirce (1955) enfatizaria a dimensão de thirdness nesse vínculo. Essa rara e difícil combinação entre ciência e intersubjetividade converteu-se no modelo ideal do fazer etnográfico, favorecendo indiretamente a combinação entre pesquisa e compromisso ético, vigente até hoje. ${ }^{7}$ Como Malinowski realizou tal proeza?

\section{O livro}

Argonautas do Pacífico Ocidental não foi a primeira publicação de Malinowski, mas tornou-se a mais conhecida. Para Malinowski, o relato etnográfico deveria levantar problemas e revelar fatos novos "de uma maneira precisa, mas não insípida". Essa orientação pautou o desenho da monografia como uma viagem imaginária pelo longo circuito das trocas do kula, o qual ele conheceu em parte pessoalmente, em parte por meio de relatos de trobriandeses.

O livro é construído de maneira engenhosa, e a estratégia resultou instigante. $\mathrm{O}$ título foi fundamental para seu lançamento, já que a designação inicial - The kula - fez o manuscrito permanecer mais de um ano sem publicação. A editora Macmillan considerou que o livro não teria apelo para o público. Já a Cambridge University Press, à qual o manuscrito foi também submetido, demandou uma contrapartida financeira considerável. Finalmente, a monografia foi publicada pela Routledge em 1922 (Malinowski, 1922).

Com um título mais expressivo, fazendo uso do termo "argonautas" como atrativo, o kula é apresentado como um evento novo no mundo dos fenômenos sociais conhecidos, mas também como apoio heurístico para conceber a tessitura da monografia. ${ }^{8}$ Monografias marcaram a história da antropologia; elas chegaram a ter um modelo canônico, do tipo "ecologia-parentesco-política-religião", especialmente durante os anos 1950-1970. No entanto, nas últimas décadas, etnógrafos têm procurado se libertar de cânones, refletindo as

7 Pels (2014) discute o caminho histórico que levou à intersubjetividade na etnografia. Harrison (2018, p. 235-236) chama a antropologia de "ciência intersubjetiva" e nota que Malinowski se via como cientista mas também como escritor (Harrison, 2018, p. 243), oscilando entre razão e intuição, racionalidade e emoção (Harrison, 2018, p. 228).

8 Mauss considera que Malinowski exagera na novidade, pois aquele tipo de troca era encontrado na Melanésia anteriormente, conforme já mencionado por Rivers. 
condições da experiência de campo. Os preceitos acadêmicos afrouxaram-se e retornou-se ao modelo flexível malinowskiano. ${ }^{9}$

Argonautas foi a primeira das cinco monografias que Malinowski publicou sobre os habitantes das Ilhas Trobriand, na Melanésia, entre 1922 e 1935. ${ }^{10}$

O kula foi, para Malinowski, o famoso "mistério etnográfico" que normalmente mobiliza o etnógrafo, mistério sempre oculto sob o aspecto trivial de tudo que o etnógrafo vê e se instiga a descobrir. Tratava-se de uma forma de troca, de origem nobre e de caráter intertribal, praticada em um circuito fechado em que longos colares (soulava) viajavam no sentido horário, e braceletes (mwali), no sentido oposto. Objetos que faziam parte do kula não deveriam ficar na posse de alguém por muito tempo, mas ser passados adiante. Assim, soulavas e mwalis estariam sempre em movimento. As transações eram públicas e cerimoniais, e as parcerias, sendo duradouras, constituíam-se em relacionamentos intertribais em larga escala.

Como uma modalidade cerimonial, o kula estava enraizado em mitos e rituais mágicos bem definidos. Embora seu objetivo principal fosse a troca de artigos sem qualquer utilidade prática - os colares poderiam ser muito longos e os braceletes, muito pequenos -, as ocasiões em que se realizavam eram com frequência propícias para trocas comerciais entre visitantes e habitantes dos lugares visitados. Ao procurar explicar o quadro geral no qual o kula fazia sentido, Malinowski lembrou-se das joias da Coroa britânica - pesadas, feias, inúteis, mas valiosas. No entanto, para os trobriandeses, diferente dos ocidentais, possuir era dar; a generosidade era sinal de riqueza.

9 O período canônico possivelmente refletiu a influência da linha mais cientificista de Radcliffe-Brown. Contudo, Evans-Pritchard (1962) rebateu Radcliffe-Brown de frente quando mencionou, em uma palestra para a BBC, que a antropologia é mais arte do que ciência. Nesse contexto, impressiona um livro de M. Young (1979), biógrafo e estudioso de Malinowski, que rearranja os dados trobriandeses seguindo as categorias "economic life, kinship, marriage, land tenure, kula", em uma violação das versões originais de Malinowski.

10 Antes, Malinowski havia publicado o ensaio “Baloma”, que Alvarez-Roldán (1995, p. 152) considera uma de suas grandes inovações: "With 'Baloma' ethnography took the form of a continuous constructive process, involving the tasks of doing fieldwork and writing-two related phases of the ethnographic process. Thanks to his experience in the Trobriands Malinowski came to revolutionize ethnography not only as a fieldwork process but also as a written product." As outras monografias são Crime and custom in savage society (Malinowski, 1926), Sex and repression in savage society (Malinowski, 1927), The sexual life of savages (Malinowski, 1929) e Coral gardens and their magic (Malinowski, 1935), em dois volumes. 


\section{O lugar do etnógrafo}

Malinowski defendeu a ideia de que os trobriandeses conheciam seus parceiros, mas desconheciam o esquema total; caberia ao etnógrafo construir o quadro geral e a síntese. Para tanto, era necessário que o investigador se preparasse para a pesquisa de campo, por meio de uma série de procedimentos elencados na conhecida introdução ao livro. Por outro lado, mencionou que, porque o kula era a atividade primária mais importante para os trobriandeses, outros fenômenos interligados, como a construção de canoas e o comércio regular, eram vistos como secundários no livro. A Malinowski interessava uma perspectiva etnográfica e não sociológica, isto é, "de dentro" e não "de fora". Nesse sentido, o kula tinha prioridade - era em função dele que datas eram marcadas, atividades definidas e expedições organizadas, assim como a grande festa cerimonial, a magia e a construção das canoas. O kula, portanto, seria o evento próprio dos trobriandeses, que ele manteve na língua nativa e não procurou traduzir, para mostrar que o via de dentro, sem a introdução de "categorias artificiais e estranhas à mente nativa". ${ }^{1}$

Era, então, a visão dos trobriandeses que importava. Ao apresentar os resultados, Malinowski fez do leitor uma espécie de cúmplice, em descrições com frequência cinematográficas: "vamos imaginar que estamos navegando..."; "entramos, agora, num mar de águas opacas e esverdeadas..."; "à medida que nosso barco penetra na laguna...". A viagem do kula é realizada pela dupla etnógrafo-leitor, em mais uma busca de intersubjetividade. Tanto quanto domina a vida trobriandesa, o kula domina o livro. As categorias ocidentais (economia, magia, mitologia) são contrastadas e impactadas pelas trobriandesas, seus questionamentos fazendo-se pelo contraste.

Em suma, Malinowski deixou delineadas duas grandes heranças para os futuros antropólogos: o desafio da procura do "ponto de vista nativo", transformado ao longo da história da disciplina em utopia; e o de fazê-lo de uma perspectiva etnográfica, interna - evitando a meramente sociológica, que seria externa.

11 Segundo Lebner (2020), Malinowski inaugura uma tradição radical que permanece até hoje, encontrada em autores diversos como Talal Asad e Marilyn Strathern. Essa tradição atenua tendências contemporâneas do cultivo de "conceitos" na antropologia. 


\section{A teoria do outro}

A revolução no projeto antropológico resultou, assim, na consideração de que o nativo tinha suas próprias ideias, suas próprias teorias. Restava, então, a tarefa de configurá-las. No caso trobriandês, o primeiro exemplo refere-se à "economia", que Malinowski questiona exatamente para contestar o conhecimento da época e situar o kula. Na medida em que se trata da "doação de um presente cerimonial em troca do qual, após certo lapso de tempo, deve ser recebido um presente equivalente" (Malinowski, 2018, p. 165), Malinowski insiste em enfatizar que a troca não é escambo (gimwali). O kula só seria considerado um escambo se o nativo agisse de maneira incorreta, apressada ou indecorosa. Nesse caso, seria criticado por agir "como se o kula fosse um gimwali".

A noção intelectual dominante na época referia-se ao "homem econômico primitivo". Supunha-se que este se movia por uma concepção racionalista de interesse pessoal, atingindo seus objetivos com um mínimo de esforços. Malinowski mostrou que, ao contrário, o trobriandês trabalhava movido por razões de natureza social altamente complexas. O kula era a prova de que o conhecimento econômico precisava de uma total revisão.

Por exemplo, a construção de canoas para uma expedição do kula exigia grande habilidade e perspicácia dos trobriandeses. Na ausência de instrumentos precisos de medição, a tecnologia era baseada em longos anos de experiência do construtor. Fórmulas mágicas, rituais simples e encantamentos em voz baixa antecipavam cada etapa da construção: os trobriandeses sabiam, insiste Malinowski, que uma canoa mal construída não alcançaria velocidade; era a magia a responsável por adiantar e apressar o resultado desejado nos estágios da construção. O primeiro estágio, de duração de dois a seis meses, consistia no vagaroso trabalho de poucas pessoas no tronco da árvore e no entalhe das tábuas da proa; o segundo, feito comunitariamente em uma ou duas semanas, incluía a montagem das pranchas e do flutuador, acompanhada de ritos e fórmulas da magia do kula executada pelo proprietário.

Estava assim definido o modo de argumentação da parte central do livro: enquanto apresentava uma viagem do kula em pormenores etnográficos, em vários momentos Malinowski intercedeu para detalhar um ou outro tópico. 
Depois da "economia" e da ideia do "homem primitivo", explicou a "sociologia", a "mitologia do kula" e pormenores técnicos da troca. No decorrer do livro, contudo, dois capítulos foram especialmente dedicados à compreensão do ponto de vista nativo e, como implicação, da "teoria do outro": os conhecidos capítulos sobre a magia do kula e o poder das palavras. Como intervalos na viagem imaginária, Malinowski avisou que leitores não interessados poderiam saltar esses capítulos e continuar a expedição.

A magia é um bom exemplo: atos mágicos e encantamentos verbais, acompanhados por ritos de impregnação ou transferência, eram realizados antes de atividades cujos resultados eram incertos. $O$ poder da magia estava relacionado com a mitologia alusiva à época dos ancestrais. Essa era a magia trobriandesa, a "teoria dos nativos de Kiriwina sobre a magia", e não, como durante muitas décadas foi considerada, a teoria da magia de Malinowski. Tampouco existiam atividades sem uma correspondente magia; a associação era íntima. Por exemplo, o trabalho e a magia eram inseparáveis porque a magia era um componente indispensável ao trabalho. Se a habilidade e o conhecimento do construtor de uma canoa não podiam ser compensados com magia, ela acrescentava algo mais, ela propiciava o resultado.

A magia trobriandesa é basicamente verbal e ligada a um fundamento psicofisiológico: a força da magia não reside nas coisas, mas está dentro do ser humano. Como vive no fundo do ventre, escapa através da voz - daí a importância das restrições alimentares para os trobriandeses, que enchem seus silos de inhames não para se fartarem, mas exatamente para não comerem. A força da magia é humana; as palavras pronunciadas e os atos têm poder porque uma pessoa qualificada para tal os enuncia. A magia trobriandesa era simples e pronunciada em voz baixa.

\section{O poder das palavras}

Quando o livro foi publicado, o capítulo sobre o poder das palavras não despertou maior entusiasmo. Avaliava-se que a chamada teoria pragmática da linguagem era uma opção de Malinowski. Esse foi mais um equívoco da época - o valor da etnografia não era bem compreendido, porque os achados de Malinowski eram, na verdade, dos trobriandeses; resultavam em uma "teoria 
nativa das palavras na magia". Para Malinowski, aprender a língua e a cultura eram tarefas relacionadas, e não apenas um dado a mais. ${ }^{12}$

Preocupado em conhecer de onde vinha o poder mágico, ele analisou as partes dos encantamentos dirigidos aos objetos, mostrando que a primeira (u'ula), breve, forte e incisiva, indicava o fundamento da magia; a segunda (tapwana) era a parte central, longa, recitada seguindo a estrutura de uma lista de palavras acrescidas de expressões-chave que se repetiam; e, finalmente, o dogina era menor, mais superficial, falado mais do que cantado, com os resultados esperados enunciados de forma "exagerada e vigorosa". ${ }^{13}$

Para Malinowski, a eficácia da fórmula resultava tanto do seu significado referencial quanto do som emitido. Assim, a magia da canoa utilizava palavras que indicavam a velocidade esperada; no kula, havia excitação, beleza, nomes de ancestrais e referências mitológicas para conquistar o parceiro. A maioria das fórmulas mágicas, notou o autor, expressava os resultados propícios que se esperavam dos encantamentos. Por outro lado, era comum o longo tapwana descrever as partes de uma canoa, ou os estágios de uma expedição, sempre acompanhados de um refrão - como uma ladainha, estimulando a eficácia da fórmula. Várias peculiaridades fonéticas estavam incluídas na magia, como mudanças na forma, palavras truncadas, partículas adicionadas e sons onomatopaicos.

Ou seja, como autores depois desenvolveriam, a linguagem é a mesma utilizada cotidianamente, mas rearranjada de forma mais simples ou mais complexa, com adições ou supressões e revisões na forma, de modo a torná-la "especial", "mágica". Igualmente importante era a cadência e a sequência das diversas fases já antecipadas pelos trobriandeses, as quais produziam uma segurança na ação mágica antecipatória, renovada nas execuções dos encantamentos.

12 De forma perceptiva, Alvarez-Roldán (1995, p. 149) comenta: "Language was not only an instrument for collecting data from informants, but also the vehicle of native thought, and therefore a means to penetrate their mentality. It was by learning the vernacular that Malinowski could gather the corpus inscriptionum kiriwineiensium he mentions in the famous Introduction to Argonauts of the Western Pacific."

13 Nas edições em português, as palavras magician e spell foram traduzidas como "feiticeiro" e "feitiço", a meu ver com conotações diferentes das que teriam "mago" e "encantamento". 


\section{O final do livro}

Depois de apresentar as transações do interior, o livro conclui que o kula seria "uma troca de tipo inteiramente novo", mas deveria existir em outros lugares do mundo. A circulação dos objetos promoveria o valor dos braceletes e dos colares a partir de um código definido pelo modo de viver, existir e pensar dos trobriandeses. A posse temporária dos objetos preciosos do kula trazia poder e conforto para os parceiros e para doentes e moribundos.

Mesmo etnograficamente nova, a troca não poderia ser única, admitia Malinowski, e possivelmente se tornaria um novo tipo de fato social, como o tabu, o totemismo, o mana: podemos esperar, diz Malinowski, encontrar "um novo tipo de propriedade, temporária, intermitente e cumulativa" em outros lugares. Assim, o kula ajudaria a banir as concepções racionalistas do "homem primitivo" e discernir sua visão do mundo, sua Weltanschauung; o kula ajudaria a conhecer outras realidades. Malinowski (2018, p. 654, grifo meu) finaliza:

Ao captar a visão essencial dos outros, com a reverência e verdadeira compreensão que se deve mesmo aos selvagens, estamos contribuindo para alargar a nossa própria visão. Não podemos chegar à sabedoria [...] e conhecer-nos a nós mesmos se nunca deixarmos os estreitos limites dos costumes, crenças e preconceitos em que todo homem nasceu.

\section{As teorias da antropologia}

Malinowski estava certo. Ao identificar a teoria do outro, ele favoreceu as teorias nossas, ou as teorias que se tornaram fundamentais para o conhecimento antropológico. Antecipava Malinowski que exemplos "tipo kula", semieconômicos e semicerimoniais, muito interessariam ao teórico. ${ }^{14}$

Marcel Mauss não demorou a aceitar a tarefa e, em 1925, divulgou seu famoso "Ensaio sobre o dom" (Mauss, 1925), em que focalizava trocas e contratos

14 Defendendo que a antropologia é uma ciência, Latour (1996) enfatiza que ela é mais produtiva quando define novas agências para a comunidade científica e compara: "The description of kula is a par with that of black holes." 
feitos por meio de presentes teoricamente voluntários, mas, na realidade, obrigatórios e de retribuição prescrita. São esses fenômenos sociais "totais", isto é, ao mesmo tempo religiosos, jurídicos, estéticos, morais e morfológicos, cujas características formam sistemas de prestações totais. Mauss usou o termo genérico potlach para designar esse tipo de troca, incluindo exemplos em várias localidades na Polinésia e na Melanésia; as Ilhas Trobriand receberam atenção especial em seu ensaio. Junto do potlach do noroeste norte-americano, estudado por Boas, Mauss desenvolveu a conhecida teoria das três obrigações, que se constitui nos atos de dar, receber e retribuir presentes em regimes diversos, desde a prestação total até o contrato individual de mercado das sociedades ocidentais.

Além da "teoria do dom", Argonautas influenciou outras disciplinas. A proposição de Roman Jakobson (1990) sobre o evento linguístico tornou-se especialmente cara aos antropólogos depois que este definiu as seis funções da linguagem: a emotiva, a conativa, a referencial, a metalinguística, a poética e, utilizando a terminologia de Malinowski, a fática - aquela função que testa o canal de comunicação, e que os trobriandeses utilizavam com frequência na magia.

Em retrospecto, detecta-se como a linguagem em ação supera e complementa a influência de Ferdinand de Saussure na antropologia, que focalizava o aspecto mental da linguagem e cuja influência foi depois marcante no estruturalismo. Malinowski insistiu que a linguagem não era apenas um processo que duplicava a realidade mental do homem, mas possuía uma parte ativa, pragmática, no próprio comportamento humano. Essa proposta esteve presente em Argonautas, mas Malinowski (1923) a explicitaria em 1923, reiterando que a análise da linguagem precisava levar em consideração "o contexto da situação", na qual ela seria um modo de ação e não apenas um contrassigno do pensamento.

Esse é um exemplo de como, na antropologia, algumas ideias transpõem limites disciplinares e depois voltam à sua origem, produzindo novas apreciações: as propostas etnográficas de Malinowski continuaram sua trajetória por décadas, expandindo-se via linguística e filosofia da linguagem antes de voltar à disciplina original. ${ }^{15}$ Um exemplo dessa propalação está na obra

15 Ver o excelente artigo de Michael Silverstein (1996). 
de John L. Austin (1961), How to do things with words, dos anos 1950, cuja influência na antropologia se tornou mais destacada nas últimas décadas.

Como inspiração de Argonautas, mais um exemplo é A grande transformação, de 1944, de Karl Polanyi (1978). Malinowski havia utilizado o exemplo trobriandês para refutar a teoria corrente do "homem econômico primitivo". Por sua vez, Polanyi recorreu aos exemplos melanésios de Malinowski para indicar como a atividade econômica esteve sempre embutida nas relações sociais. No mundo moderno, a mudança fundamental consistiria no fato de que a sociedade havia se tornado acessória da economia.

\section{Diário e cartas}

Enquanto fazia pesquisa entre os trobriandeses, Malinowski seguiu uma das prescrições que havia feito na introdução à monografia: a de que o etnógrafo deve elaborar um diário de campo. Seu diário foi escrito em polonês, sua língua materna, com expressões em várias outras (como alemão, francês, grego, espanhol, latim e línguas melanésias) e mantido reservado até 1967. Quando foi publicado, criou perplexidade e alvoroço entre os antropólogos. Afinal, o modelo do grande etnógrafo não era imune às fraquezas humanas? Onde ficava a retitude do etnógrafo que mantinha pensamentos eróticos no campo, ou, ferindo nossa sensibilidade atual, que chamava os melanésios de niggers? Mesmo se sabendo que o diário não tinha como objetivo a publicação, o escândalo desencadeou reações imediatas.

A introdução de Raymond Firth (1967) ao Diary in the strict sense of the term (Malinowski, 1967), publicado mediante licença da segunda mulher de Malinowski, foi extremamente cuidadosa, mas não impediu a desaprovação de Clifford Geertz (1967) poucos meses depois, em "Under the mosquito net". Passado um ano, George Stocking Jr. (1968) procurou conter o dano à reputação de Malinowski mostrando, em "Empathy and antipathy in the Heart of Darkness", como a impaciência, a irritação, a hipocondria, os devaneios sexuais e os termos depreciativos em relação aos nativos eram anotados nos momentos de grande frustração com a pesquisa.

O diário não acompanha todo o período de pesquisa entre os trobriandeses e há grandes intervalos entre as entradas. Ele pode desapontar o leitor 
simplesmente curioso porque a maioria das anotações é telegráfica, contendo menções pessoais a disposição física, sono, remédios, viagens pelas ilhas, dúvidas amorosas tanto quanto etnográficas, exercícios de canoagem. Exortações ao trabalho são uma constante em todo o diário, indicando a determinação de Malinowski.

Talvez porque na época da publicação não se conheciam as cartas então trocadas entre Malinowski e sua noiva, Elsie Masson, perdeu-se um dos elementos-chave para a compreensão do diário. As cartas só foram publicadas em 1995 por Helena Wayne (1925-2018), a caçula das três filhas do casal. Os dois documentos, diário e conjunto de cartas, indicam com clareza o quadro emocional de Malinowski e sua disposição para se questionar. Surpreende, então, a brutal honestidade consigo mesmo e com a noiva. Em uma verdadeira autoanálise, revelam-se "debates morais, disposições dostoievskianas, alusões conradianas, [...] desejos sexuais frustrados, explosões racistas e misantrópicas" (Young, 2014, tradução minha), enfim, vários aspectos desagradáveis de seu caráter ${ }^{16}$ Como Malinowski escreveu justamente com o objetivo de interpelar a si próprio, traços negativos de sua personalidade foram naturalmente ressaltados; eram esses os aspectos que queria desnudar e, eventualmente, modificar.

Torna-se assim possível observar, no diário, a ambiguidade do etnógrafo, ora questionando seu próprio caráter, ora considerando seu futuro promissor. Por exemplo, embora escreva, em 5 de junho de 1918, "external ambition. When I think of my work [...] or the revolution I want to effect in social anthropology - this is a truly creative ambition" (Malinowski, 1967, p. 289), três meses depois, em 18 de setembro, ao lembrar-se da mãe recém-falecida e de uma antiga namorada a quem não conseguira dizer que se casaria com Elsie, encerra o diário com a conclusão de que "truly I lack real character" (Malinowski, 1967, p. 298). ${ }^{17}$

O mesmo pode ser dito das cartas entre Malinowski ("Bronio", como era conhecido pela família e por amigos) e sua noiva Elsie, que também pareciam um diário, revelando igual franqueza. Em 29 de novembro de 1917, por exemplo, Bronio fala sobre memórias de experiências sensuais e eróticas, mais comum a

16 Diz Young (2014) sobre o diário: “Against his daughters' wishes [...] his widow published a translation [of the Diary]. [...] It would become the most infamous, most nakedly honest document in the annals of social anthropology."

17 Ver Young (2014). 
homens por suas "experiências de vida", ao que Elsie responde: "I know that the desire to attract and be attracted does not die out because of a deeper attachment." Ao tentar converter a noiva a aderir aos diários, não tem muito sucesso; ela diz que escrever para ele já é seu diário.

As cartas entre os dois têm continuidade e representam 19 anos de diálogo, desde o momento em que se conhecem até a morte prematura de Elsie, vítima de esclerose múltipla. Na introdução, a filha Helena Wayne diz que manteve os termos niggers e niggs porque, embora já não fossem termos "de salão", eram comumente usados pelos comerciantes brancos que eram contatos e companheiros de Malinowski no campo. E justifica: "The word and the idea are offensive to us now but to eliminate it would have been a falsification and a distortion of the world nearly eighty years behind us" (Wayne, 1995, p. x). ${ }^{18}$

\section{Reanálises como homenagens}

Como em geral a história da antropologia indica suas transformações na sequência de monografias etnográficas desde o início do século XX, tornou-se corriqueiro que dados etnográficos passassem a ser alvo de reanálises. Algumas vezes elas são explicitamente críticas, indicando equívocos no original. Mas outras, baseadas em dados presentes nas monografias, permitem avançar, complementar ou ampliar as análises originais; essas se transformam em homenagens aos etnógrafos originais. Foi o que aconteceu com a etnografia trobriandesa.

Durante as décadas de 1960 a 1980, as reanálises surgiram: Edmund Leach (1958) escreveu sobre os clãs trobriandeses e a categoria de parentesco tabu, mas no livro Rethinking anthropology, de 1961, criticou a falta de generalização

18 Ler a monografia hoje naturalmente demanda reconhecer o contexto histórico do colonialismo. Harrison (2018, p 234) observa: "[...] coming from a context that represented the pinacle of coloniality, despite his dislike for missionaries and misgivings about the colonial enterprise, it would have been impossible for Malinowski to be anything but colonial". Utilizar privadamente termos como niggers e niggs contrasta com passagens em que Malinowski aponta o discernimento dos nativos. Escrevendo para Seligman, diz: "My work is going fairly smoothly, though I will have now a somewhat hard time because I had to part with my interpreter [...]. But I have got so much Kiriwinian [...] \& having extremely intelligent natives to deal with, I am able always to get out of the difficulty" (cf. Alvarez-Roldán, 1995, p. 148, grifo meu). 
comparativa de Malinowski (Leach, E., 1961). Seguiu-se a controvérsia clássica despertada pelo artigo "Virgin birth" na revista Man, durante os anos 1968-1969, de que participaram vários antropólogos reconhecidos na época. ${ }^{19}$ Mais tarde, em 1977, Leach considerou Malinowski "o maior e mais original de todos os antropólogos sociais" (Leach, 1977 apud Tambiah, 1989, p. 311). Jerry Leach e Edmund Leach (1983) apresentaram resultados de pesquisas então recentes sobre o kula, comparando-os a Argonautas. ${ }^{20}$ Uberoi (1962) analisou os resultados de Malinowski, e Spiro (1982) argumentou, contra Malinowski em seu diálogo com Freud, que os dados trobriandeses sugeriam a presença de um forte complexo de Édipo. Lounsbury (1965) defendeu Malinowski das críticas de Leach e complementou a terminologia de parentesco trobriandesa. Em 1968, Tambiah reanalisou o poder das palavras na magia trobriandesa em seu aspecto semântico e pragmático (Tambiah, 1968) e, em 1985, apresentou a cosmologia trobriandesa a partir dos poderes extraordinários das bruxas voadoras (Tambiah, 1985). Weiner (1976) focalizou o papel das mulheres na troca trobriandesa e Tooker (1986) indicou a natureza sexual do kula.

Diretos e indiretos, esses vários tributos a Malinowski seguiram um momento difícil. Foi quando, em 1957, publicou-se uma avaliação de sua obra por ex-alunos, muitos dos quais revelaram ambivalência perante o antigo mestre (Firth, 1957). Man and culture causou constrangimento porque, tendo sido Malinowski um professor brilhante e carismático, o livro deixa claro que as opiniões não eram unânimes. A introdução conciliadora de Firth explica a hesitação a partir de três razões principais: primeiro, o prestígio das ideias de A. R. Radcliffe-Brown naquele momento, com sua abordagem estrutural, considerada mais científica; segundo, a fragilidade da ideia de cultura em Malinowski; e, finalmente, as qualidades pessoais do etnógrafo, para quem a honestidade intelectual era um valor supremo. Extrovertido e intolerante para muitos, Malinowski encontrou hostilidade explícita em vários de seus antigos alunos.

19 Entre eles, Melford Spiro, Phyllis Kaberry, H. A. Powell, R. M. Dixon, Kenneth Burridge, E. Schwimmer, Mary Douglas, Peter Wilson, Wyatt MacGaffey e Rodney Needham.

20 Seis décadas depois da tentativa fracassada de Malinowski, o título The kula foi finalmente utilizado com sucesso. A introdução de Jerry Leach (1983) ao volume organizado em 1983 traz informações sobre as primeiras observações sobre o kula e inclui comentários à recepção de Argonautas pelos (poucos) habitantes trobriandeses que leram a monografia. 


\section{Quem foi Malinowski}

Bronislaw Kasper Malinowski nasceu em Cracóvia, Polônia, em 7 de abril de 1884, filho único de Józefa e Lucjan Malinowski. O pai era linguista e etnógrafo, professor de filologia eslavônica na Universidade de Cracóvia. ${ }^{21} \mathrm{Na}$ época, a Polônia era dividida entre os impérios russo, alemão e austríaco. Cracóvia era a capital da Galícia austríaca, onde florescia uma acentuada vida artística e intelectual.

A mãe de Malinowski, uma mulher instruída, e a família materna exerceram forte influência na sua criação. Por ter perdido o pai aos 14 anos, e por sua saúde frágil, Bronio passou a viajar para estações de água com frequência em companhia da mãe: Itália, ilhas mediterrâneas e norte da África, Madeira e Ilhas Canárias. Essas viagens foram formativas e, antes dos 18 anos, ele falava italiano, alemão e espanhol, além do polonês.

Ao entrar na Universidade da Cracóvia, escolheu inicialmente física e matemática e, depois, psicologia e filosofia. Na Universidade de Leipzig, estudou economia e Völkerpsychologie. Foi aos 26 anos que decidiu reunir seus conhecimentos e estudar antropologia. Com essa finalidade, foi para a London School of Economics (LSE), aprendeu inglês rapidamente, e lá permaneceu quatro anos sob a orientação de Charles G. Seligman.

O primeiro livro de Malinowski, The family among the Australian aborigines, baseado em fontes bibliográficas, foi publicado em Londres em 1913 (Malinowski, 1913). No ano seguinte, sob recomendação de Seligman e com fundos da LSE e do industrial Robert Mond, ele compareceu como delegado à conferência internacional da Sociedade Britânica para o Progresso da Ciência, realizado em quatro cidades australianas. Ao desembarcar, contudo, tornou-se imediatamente um enemy alien por seu vínculo ao império austríaco. A guerra havia sido declarada na Europa durante a viagem. Ao chegar, seu grande amigo Stanislaw Witkiewicz,

21 As informações biográficas que se seguem foram condensadas de várias vinhetas introdutórias escritas por Helena M. Wayne (1995, v. 1, 2) ao longo da publicação das cartas trocadas entre seus pais. Foram também incluídos dados apresentados em Young (1998, 2014). Kuper (1973, p. 36-37) traz alguns eventos pitorescos, como a troca de bilhetes entre Malinowski e Bertrand Russell a respeito de um singelo chapéu deixado pelo primeiro na saleta do segundo. 
que serviria como fotógrafo na pesquisa, voltou para a Polônia para lutar com os russos contra a Alemanha. ${ }^{22}$

Os planos de pesquisa de Malinowski não mudaram e ele foi apoiado por dois eminentes professores, Sir Baldwin Spencer e Sir Edward Stirling, que o encorajaram a seguir para a Nova Guiné assim que a conferência terminou. Foi o professor Sterling quem apoiou a publicação dos primeiros resultados da pesquisa no artigo "The natives of Mailu", que rendeu a Malinowski o título de doutor em ciência da London University. Em 1915, seguiu direto para as Ilhas Trobriand, onde ficou um ano, marcando o início do padrão de pesquisa de campo prolongada. ${ }^{23}$

Malinowski conheceu Elsie em 1916, durante um jantar na casa do pai dela, o professor David Orme Masson (mais tarde "Sir"), um dos organizadores do encontro da Sociedade Britânica de 1914. Ela havia publicado pela Macmillan, em Londres, uma coletânea de artigos jornalísticos, An untamed territory, sobre a fronteira australiana. Trocar cartas foi uma atividade importante na relação entre os dois, intensificada durante a pesquisa trobriandesa. As cartas rememoram os passeios, jantares e encontros antes da segunda pesquisa trobriandesa, e marcam a decisão de Elsie de estudar enfermagem e trabalhar no plantão do Hospital de Melbourne durante a guerra. Na época da segunda pesquisa entre os trobriandeses, já era profundo o vínculo desenvolvido entre os dois; os diários de campo e as cartas revelam os sentimentos mútuos.

Ao se casarem em 1919, contra a vontade dos pais de Elsie, ambos concordavam sobre o significado do casamento: o trabalho sério, a necessidade e o prazer da música, a alegria de crianças. Ambos compartilhavam "uma aversão pelo que parecia espalhafatoso para eles nos anos do pós-guerra e um anseio por tudo que ainda era genuíno e intocado pelo mundo industrial" (Wayne, 1995, p. xvi-xviii, tradução minha). Antes de se casar, diz Wayne, Elsie sabia que o futuro não seria calmo e predizível, mas sem dúvida seria interessante. Uma grande diferença existia entre os dois: o caráter dele era cheio de contradições

22 Para a longa amizade e rivalidade entre "Bronio" e "Stás", ver Skalník (1995).

23 Para celebrar o centenário da chegada de Malinowski às Ilhas Trobriand, realizou-se um seminário na Libera Università di Bolzano, na Itália, no Malinowski Forum for Ethnography and Anthropology. Ver Strathern (2018) para um dos trabalhos sobre a presença dos trobriandeses na ocasião e para as condições coloniais ("infraestruturas") que possibilitaram a pesquisa de Malinowski. 
e discrepâncias; o senso de humor dela equilibrava e limitava o dano que ele produzia nas relações. Em 1928, Elsie foi diagnosticada com esclerose múltipla, doença que a afligia havia algum tempo.

Malinowski escreveu Argonautas em quatro meses. Estando ele em Londres e sem uma posição acadêmica regular, e Elsie vivendo provisoriamente em Edimburgo com a primeira filha recém-nascida, o casal decidiu passar o inverno europeu nas Ilhas Canárias. Com a meta de escrever 4 mil palavras por dia, o texto de The kula foi finalizado em abril de 1921.

Seguiram-se duas recusas: a editora Macmillan considerou o texto com muito valor científico, mas sem expectativa de venda; a Cambridge University Press também negou a publicação, a menos que houvesse um considerável subsídio. Partiu de Seligman a ideia de submeter o financiamento à LSE caso Malinowski oferecesse um curso sobre o kula na primavera de 1922. Em 20 de julho daquele ano, Elsie recebia sua cópia com a dedicatória: “To my collaborator, who had half the share at least and more than half the merit in writing this book." A segunda filha havia nascido em Cassis, na França, onde tinham alugado uma casa depois de Tenerife.

Nesse ínterim, Malinowski considerava um convite para ocupar uma cátedra na Polônia, mas o casal não se animou com a pobreza pós-guerra durante uma curta viagem ao país. Decididos a procurar outro lugar de residência, quente e módico, seguiram a recomendação do amigo Paul Khuner de uma cidadezinha ao sul do Tirol - uma região anteriormente parte do império austro-húngaro, falante de alemão, que havia sido cedida à Itália depois da guerra. Durante o inverno de 1922-1923, mudaram-se provisoriamente para uma casa antiga, onde Malinowski continuou a trabalhar no material trobriandês e Elsie escreveu artigos para jornais ingleses e australianos sobre a situação econômica da Polônia e o início da ascensão do fascismo com Mussolini.

Durante esse período, a LSE ofereceu uma posição permanente a Malinowski como Reader in Social Anthropology, que ele aceitou, mas só a partir de 1924-1925. Precisava cuidar da saúde e trabalhar o material bruto trobriandês ainda intocado. O casal decidiu então se fixar em Oberbozen e, com melhores finanças e ajuda de um empréstimo, comprar uma casa. Lá nasceu a terceira filha. Em Londres, onde iniciou sua carreira no outono de 1924, Malinowski morou em pensões em Bloomsbury, perto da LSE, viajando para o norte da Itália assim que as aulas terminavam. Em Oberbozen, mesmo em férias, recebia 
estudantes que se hospedavam nas redondezas. Foi um professor engajado, dirigindo um concorrido seminário na London School.

Iniciando com Argonautas, Malinowski publicou o restante da etnografia trobriandesa até a morte de Elsie, em 1935: Crime and custom in savage society, em 1926; Sex and repression in savage society, em 1927; The sexual life of savages, em 1929; Coral gardens and their magic, em dois volumes, em 1935. Coral gardens, dedicada a Elsie, que ela não chegou a ver publicada, foi a obra predileta do autor, mas de pouca venda. É possível imaginar que, devido a uma vida de dificuldades financeiras, e com a experiência anterior da publicação dificultada pelo título The kula, Malinowski tenha optado por adotar títulos atrativos para o público em geral, visando a um retorno monetário. Coral gardens interrompeu essa tendência.

Professor carismático, personalidade poderosa, conferencista magnético, para alguns sua intolerância era opressiva. Malinowski teve uma vida de muitas viagens, amizades, conexões com intelectuais e artistas, plena de títulos e convites para conferências e eventos. Quando voltou a Londres depois da pesquisa de campo, circulou em altas redes intelectuais; conviveu com autores conhecidos, relacionou-se como os Frazers, os Seligmans, Rivers, Bertrand Russel.

Malinowski passou seus últimos anos nos Estados Unidos. Chegou em outubro de 1938 para um ano sabático, mas o início da Segunda Guerra fê-lo perceber que o conflito seria prolongado; sua origem polonesa continuava a criar-lhe dificuldades. Embora relutante em se afastar da LSE, aceitou um convite da Universidade de Yale, em New Haven, depois de manter negociações com Harvard, em Cambridge, Massachusetts (de onde recebera o título de doutor honorário em 1936), Duke University, na Carolina do Norte, e New School of Social Research, em Nova York. Lá viveu acompanhado de sua segunda mulher, a pintora Valetta Swann, e as três filhas do casamento com Elsie. Depois de três anos como professor temporário, foi admitido como permanente, mas não chegou a assumir o cargo. Faleceu subitamente, vítima de um ataque cardíaco, em 16 de maio de 1942. 


\section{Referências}

ALVAREZ-ROLDÁN, A. Malinowski and the origins of the ethnographic method. In: VERMENTER, H. F.; ALVARES-ROLDÁN, A. (ed.). Fieldwork and footnotes: studies in the history of European anthropology. London: Routledge, 1995. p. 143-155.

AUSTIN, J. L. How to do things with words: the William James Lectures delivered at Harvard University in 1955. Cambridge: Harvard University Press, 1961.

BRITISH ASSOCIATION FOR THE ADVANCEMENT OF SCIENCE. Notes and queries on anthropology. 4th ed. London: The Royal Anthropological Institute, 1912.

DASTON, L.; GALLISON, P. Objectivity. New York: Zone Books, 2007.

EVANS-PRITCHARD, E. E. Social anthropology and other essays. New York: The Free Press, 1962. (BBC Third Programme Lectures 1950).

FIRTH, R. (ed.). Man and culture: an evaluation of the work of Bronislaw Malinowski. London: Routledge \& Kegan Paul, 1957.

FIRTH, R. Introduction. In: MALINOWSKI, B. A diary in the strict sense of the term. London: Routledge \& Kegan Paul, 1967. p. xi-xix.

GEERTZ, C. Under the mosquito net. The New York Review of Books, New York, 14 Sept. 1967.

GEERTZ, C. Local knowledge: further essays in interpretive anthropology. New York: Basic Books, 1983.

HARRISON, A. K. Ethnography. In: HARRISON, A. K. Ethnography: understanding qualitative research. Oxford: Oxford University Press, 2018. p. 223-253.

JAKOBSON, R. On language. Edited by Linda R. Waugh and M. Monville-Burston. Cambridge: Harvard University Press, 1990.

KUPER, A. Anthropologists and anthropology: the British School 1922-1972. New York: Pica Press, 1973.

LANDTMAN, G. The Kiwai Papuans of British New Guinea. London: Macmillan, 1927.

LATOUR, B. Not the question. Anthropology Newsletter, [s. l.], v. 37, n. 3, Mar. 1996. Sem paginação.

LEACH, E. Concerning Trobriand clans and the kinship category Tabu. In: GOODY, J. (ed.). The developmental cycle in domestic groups. Cambridge: Cambridge University Press, 1958. p. 120-145. 
LEACH, E. Rethinking anthropology. London: Athlone, 1961.

LEACH, J. W. Introduction. In: LEACH, J.; LEACH, E. (ed.). The kula: new perspectives on Massim exchange. Cambridge: Cambridge University Press, 1983. p. 1-26.

LEACH, J.; LEACH, E. (ed.). The kula: new perspectives on Massim exchange. Cambridge: Cambridge University Press, 1983.

LEBNER, A. No such thing as a concept: a radical tradition from Malinowski to Asad and Strathern. Anthropological Theory, [s. l.], v. 20, n. 1, p. 3-28, 2020.

LOUNSBURY, F. Another view of the Trobriand kinship categories. American Anthropologist, [s. l.], v. 67, n. 5, p. 142-185, 1965.

MALINOWSKI, B. The family among the Australian aborigenes. London: University of London Press, 1913.

MALINOWSKI, B. Argonauts of the Western Pacific: an account of native enterprise and adventure in the archipelagoes of Malanesian New Guinea. London: Routledge, 1922.

MALINOWSKI, B. The problem of meaning in primitive languages. In: OGDEN, C. K.; RICHARDS, I. A. The meaning of meaning. London: Routledge \& Kegan Paul, 1923. p. 296-336.

MALINOWSKI, B. Crime and custom in savage society. London: Routledge, 1926.

MALINOWSKI, B. Sex and repression in savage society. London: Routledge, 1927.

MALINOWSKI, B. The sexual life of savages in Northwestern Melanesia. London: Routledge, 1929.

MALINOWSKI, B. Coral gardens and their magic. Bloomington: Indiana University Press, 1935. 2 v.

MALINOWSKI, B. A diary in the strict sense of the term. London: Routledge \& Kegan Paul, 1967.

MALINOWSKI, B. Argonautas do Pacífico Ocidental. Tradução Anton P. Carr, Lígia Cardieri. São Paulo: Ubu, 2018.

MAUSS, M. Essai sur le don. L’Année Sociologique: nouvelle série, Paris, t. 1, p. 30-186, 1925.

PEIRCE, C. Philosophical writings of Peirce. Selected and edited with an Introduction by Justus Buchler. New York: Dover, 1955. 
PELS, P. After objectivity: an historical approach to the intersubjective in ethnography. Hau: journal of ethnographic theory, [s. l.], v. 4, n. 1, p. 211-236, 2014.

PINA-CABRAL, J. de. 'Anthropology' challenged: notes for a debate. Journal of the Royal Anthropological Institute, [s. l.], v. 12, p. 663-673, 2006.

POLANYI, K. The great transformation: the political and economic origins of our time. Boston: Beacon Press, 1978.

SILVERSTEIN, M. Language as a part of culture. In: TAX, S. (ed.). Horizons of anthropology. 2nd ed. Chicago: Aldine, 1996. p. 119-131.

SKALNÍK, P. Bronislaw Kasper Malinowski and Stanislaw Ignacy Witkiewicz. In: VERMENTER, H. F.; ALVAREZ-ROLDÁN, A. (ed.). Fieldwork and footnotes: studies in the history of European anthropology. London: Routledge, 1995. p. 129-142.

SPIRO, M. Oedipus in the Trobriands. Chicago: The University of Chicago Press, 1982.

STOCKING JR., G. W. Empathy and antipathy in The Heart of Darkness. Journal of the History of the Behavioral Sciences, [s. l.], v. 4, p. 189-194, 1968.

STOCKING JR., G. W. The ethnographer's magic: fieldwork from Tylor to Malinowski. In: STOCKING JR., G. W. (ed.). Observers observed: essays on ethnographic fieldwork. Madison: The University of Wisconsin Press, 1983. p. 70-120.

STRATHERN, M. Infrastructures in and of ethnography. ANUAC, [s. l.], v. 7, n. 2, p. 49-69, 2018.

TAMBIAH, S. J. The magical power of words. Man, [s. l.], v. 7, n. 3, p. 175-208, 1968.

TAMBIAH, S. J. On flying witches and flying canoes: the coding of male and female values. In: TAMBIAH, S. J. Culture, thought and social action. Cambridge: Harvard University Press, 1985. p. 287-315.

TAMBIAH, S. J. Edmund Ronald Leach, 1910-1989. Proceedings of the British Academy, [s. l.], v. 97, p. 293-344, 1989.

TOOKER, D. When gender moves around: the sexual nature of kula. Special paper. Cambridge: Harvard University, 1986. Manuscrito.

UBEROI, J. P. S. Politics of the kula ring: an analysis of the findings of Bronislaw Malinowski. Manchester: Manchester University Press, 1962.

WAYNE, H. M. (ed.). The story of a marriage: the letters of Bronislaw Malinowski and Elsie Masson. London: Routledge, 1995. 2 v. 
WEINER, A. Women of value, men of renown: new perspectives in Trobriand exchange. Houston: University of Texas Press, 1976.

YOUNG, M. W. (ed.). The ethnography of Malinowski. London: Routledge, 1979.

YOUNG, M. W. Malinowski’s Kiriwina: fieldwork photography 1915-1918. Chicago: The University of Chicago Press, 1998.

YOUNG, M. W. Writing his life through the Other: the anthropology of Malinowski. The Public Domain Review, [s. l.], 22 Jan. 2014. Disponível em: https://publicdomainreview.org/essay/writing-his-life-through-the-other-the-anthropology-of-malinowski. Acesso em: 5 mar. 2021.

Recebido: 09/03/2021 Aceito: 15/03/2021 | Received:3/9/2020 Accepted:3/15/2021 